\title{
Peri-abortion contraception: a qualitative study of users' experiences
}

Usha Kumar, MRCOG, DFFP, Specialist Registrar; Paula Baraitser, MB BS, MFFP, SCMO; Sheila Morton, RGN, RM, Women's Health Researcher; Helen Massil, MRCOG, MFFP, Consultant, Department of Sexual and Reproductive Health, Southwark Primary Care Trust, London, UK

Correspondence: Dr Usha Kumar, Department of Sexual and Reproductive Health, Southwark Primary Care Trust, St Giles Hospital, St Giles Road, London SE5 7RN, UK. E-mail: akumar5902@aol.com

(Accepted 21 October 2003)

Journal of Family Planning and Reproductive Health Care 2004; 30(1): 55-56

\begin{abstract}
Background. Contraceptive counselling is an essential element of induced abortion services but concerns remain about its effectiveness.

Objective. The issues that influence peri-abortion contraception were explored as part of a study on the experiences of women undergoing induced abortion.

Method. In-depth interviews with 21 women of varying ages, gestations and ethnicity, 3-9 weeks after termination of their pregnancy, with qualitative analysis of data.

Results. Contraceptive risk-taking was high both before and after abortion. After abortion, only a few women had changed either to using some method, or moving to more reliable methods. Health professionals had not explored the issues around contraception with sufficient clarity or detail to be effective. Discussion of contraception was often deferred to the post-abortion follow-up visit, which only 12 respondents had attended at the time of interview.

Conclusions. The effectiveness of peri-abortion contraception counselling was disappointing. We suggest that a family planning-trained outreach nurse attached to abortion providers with specific responsibility for contraception could improve uptake post-abortion.
\end{abstract}

\section{Introduction}

Contraceptive counselling is an essential element of induced abortion services ${ }^{1}$ but concerns remain about its effectiveness. 2,3

As part of a qualitative study on women's experiences of abortion in the National Health Service (NHS) we investigated their contraceptive use before termination of pregnancy (TOP), the contraceptive advice they had received in the peri-abortion period and its influence on their contraceptive use post-TOP.

\section{Background and method}

In-depth interviews were conducted with 21 women of varying ages, gestations and ethnicity, 3-9 weeks after termination of their pregnancy, with qualitative analysis of data. Details of background and methodology are discussed in a related article. 4

\section{Results}

Contraception before abortion

Contraception before abortion was predictably suboptimal (Table 1). Several women had been taking contraceptive risks for months or years before their unwanted pregnancy and had assumed that their fertility was low.

"When I was younger I used to have the pill at night. It was terrible. I used to get up and take like five at a time but I never got pregnant so I didn't think I was particularly fertile."
Some women had limited or no knowledge of contraception or of local family planning services. Those who had recently moved into the area had not registered with a general practitioner (GP) until they sought a referral for TOP. Others had used contraception in the past but had stopped because of side effects, misconceptions or difficulties using the methods, or because they were no longer in a relationship.

"I used to have this contraceptive injection in my bottom and you've got to have a rest from it; that's when I fell pregnant, when I had a rest from the injection."

Awareness of the emergency contraceptive pill was generally good but reasons for not accessing it included not having a GP, difficulty getting emergency appointments and limited opening hours of surgeries, prohibitive costs for over-the-counter purchase, and misconceptions that it could only be used a limited number of times.

"[In the past] I bought it [emergency contraception] from the chemist. It was extremely expensive, I was very shocked actually."

Table 1 Contraceptive use before and after TOP

\begin{tabular}{|c|c|c|c|}
\hline $\begin{array}{l}\text { Age } \\
\text { (years) }\end{array}$ & Parity & $\begin{array}{l}\text { Contraception } \\
\text { pre-TOP }\end{array}$ & $\begin{array}{l}\text { Contraception post-TOP } \\
\text { (method in use at the } \\
\text { time of interview) }\end{array}$ \\
\hline 37 & Para 2, 2 miscarriages & Condom ${ }^{\mathrm{a}}$ & Condom \\
\hline 24 & Para 0 & Condom ${ }^{b}$ & Injection \\
\hline 21 & Para 0 & None & None \\
\hline 31 & Para 0 & None & Pill \\
\hline 21 & Para 1 & None & Condom \\
\hline 23 & Para 0,1 TOP & Condom ${ }^{b}$ & Condom \\
\hline 31 & Para 0,1 TOP & None & Pill \\
\hline 32 & Para 0 & Condom ${ }^{a}$ & Condom \\
\hline 35 & Para 2 & Persona $^{b}$ & Condom \\
\hline 16 & Para 0 & Pillb & Pill \\
\hline 20 & Para 0 & None & None \\
\hline 27 & Para 0 & None & None \\
\hline 40 & Para 2 & None & None \\
\hline 21 & Para 0 & Condoma & Condom \\
\hline 32 & Para 0 & Condom $^{\mathrm{a}}$ & Pill \\
\hline 32 & Para 0,1 TOP & Pillb & None \\
\hline 25 & Para 1,1 TOP & None & None \\
\hline 21 & Para 0 & Condom $\mathrm{b}$ & None \\
\hline 21 & Para 0 & Condom ${ }^{\mathrm{a}}$ & Pill \\
\hline 36 & Para 1 & Pilla & Condom \\
\hline${ }_{-}^{c}$ & _ & Rhythm & Rhythm \\
\hline
\end{tabular}

aMethod failure.

bUser failure.

cClient did not complete the interview on account of emotional distress.

TOP, termination of pregnancy. 
"I've used the morning-after pill but they're only meant to be used a certain number of times because they don't like you using it every time."

\section{Contraception post-abortion}

Although many respondents found the abortion stressful and were keen not to repeat this experience, contraceptive use after the abortion remained poor. At the time of the interview only six women had changed either from not using contraception previously to using some method, or from condoms to more effective methods. There is a sense that the contraceptive problems that led to an unplanned pregnancy in the first place had remained unresolved.

"The first pill I had that they gave me after the operation, I missed three pills, I don't even know if it has worked or not 'cause I'm really rubbish at taking them."

In the process of obtaining an abortion, women met health care professionals at referral, at pre-TOP assessment and on the day of the abortion. The extent of contraceptive counselling that they received at each stage was variable. Some referring doctors had discussed contraception but most had not.

"I think she [the GP] was leaving contraception to XX [the abortion provider]or whoever."

Although the issue of future contraception had been raised with all women at discharge after their TOP, this had not necessarily led to initiation of effective contraception in most cases. The inability of women to come to a decision in this regard and understand instructions for use within the short time available could have partly accounted for this. Also, such counselling was likely to be ineffective if provided at discharge during an emotionally stressful period without firm plans having been made previously.

"She [the nurse in the day surgery unit] said to me what am I going to use after this. But I was just going to leave. I don't think that was the question to ask in that time. I think that question was a bit, you know, talking question, not just saying yes or no."

Abortion service providers may lack time or training to provide adequate contraceptive counselling and it appeared that excessive reliance was placed on the 2 -week follow-up appointment with the GP. This was particularly inappropriate for those women whose request for an abortion had made their relationship with their GP difficult.

"They just asked what contraception I was going to use and I said the pill. So they didn't actually give me any more information. I think they left that to me to chase it up with my GP."

Where the NHS contracts abortion services to voluntary sector providers, women may not realise that this covers free contraception.

"But then because XX is a private place they couldn't fix it [the IUD] 'cause I have to pay and I haven't got money to pay. Yeah because in the leaflet it said if I'm having this done I have to pay for it."

Women undergoing TOP receive significant amounts of new information about the abortion process and may not retain contraceptive advice unless reinforced with a confirmed follow-up appointment.

"I don't know if I have to go [for follow-up] to the same place, or I have to go to my doctor, I don't know."

Twelve out of the 21 women studied had attended for a follow-up either with their GP or at a family planning clinic (FPC) after 2 weeks. These visits had helped some women to address problems related to side effects, or to obtain contraceptive supplies.

\section{Discussion}

The National Audit of Induced Abortion indicated that 88\% of abortion-service provider units in England and Wales provided patients with contraceptive advice, and that in $81 \%$ of units this was given by a trained person. ${ }^{5}$ There is, however, no information on the extent of contraceptive uptake and continuation by clients.

Garg et al. reported that previous TOPs had not induced a change to more effective methods of contraception and suggested more thorough peri-abortion contraception counselling with structured follow-up. ${ }^{2}$ Their survey found variation in the content of advice given to women undergoing abortion, with only $40 \%$ receiving a comprehensive discussion on contraceptive options in relation to individual circumstances, and follow-up arranged for less than half of the women. ${ }^{2}$

In the model studied, general responsibility for periabortion contraception counselling rested with professionals at primary care level and at the abortion provider unit. Our data highlight the ineffectiveness of such a system where there was no clarity of role, with a tendency for health professionals to assume that the next person along the line would deal with contraception. Also, there was over-reliance on the post-abortion follow-up appointment which clients were expected to organise themselves.

Effective contraceptive counselling is time consuming and may be impractical within the time available to staff during the referral visit, at pre-TOP assessment or at abortion. It may therefore be appropriate to assign the role of contraceptive counselling to a specialist outreach nurse attached to the abortion service provider. The nurse's role should be specific to discussing contraception at preabortion assessment to facilitate initiation of a reliable method following the abortion, with follow-up and a link to mainstream contraceptive service providers such as GPs and FPCs. This model of proactive and targeted outreach has been successful elsewhere in linking young people to contraceptive services. ${ }^{6}$ In addition, the integration of family planning and TOP services, which already exists in parts of the country, would also facilitate contraception uptake.

\section{Acknowledgements}

The authors are grateful to the staff from the three abortion provider units in the area studied for their co-operation in this study and to the women who kindly agreed to take part in the study.

\section{Statements on funding and competing interests}

Funding. This study was funded by the Guy's and St Thomas' Charitable Foundation.

Competing interests. None identified.

References

1 Royal College of Obstetricians and Gynaecologists (RCOG). The Care of Women Requesting Induced Abortion. Evidence-based Guideline No. 7. London: RCOG, 2000.

2 Garg M, Singh M, Mansour D. Peri-abortion contraceptive care: can we reduce the incidence of repeat abortions? J Fam Plann Reprod Health Care 2001; 27: 77-80.

3 Meyrick J. Repeat use of contraceptive crisis services among adolescent women. J Fam Plann Reprod Health Care 2001; 27: $33-36$

4 Kumar U, Baraitser P, Morton S, et al. Decision making and referral prior to abortion: a qualitative study of women's experiences. $J$ Fam Plann Reprod Health Care 2004; 30: 51-54.

5 Royal College of Obstetricians and Gynaecologists (RCOG). National Audit of Induced Abortion 2000 - Report of England and Wales. London: RCOG, September 2001.

6 Baraitser P, Fettiplace R, Dolan F, et al. Quality mainstream services with proactive and targeted outreach: a model of contraceptive service provision for young people. J Fam Plann Reprod Health Care 2002; 28: 90-94. 